\title{
Effect of calcination temperature on electrical properties of $\mathrm{Nd0.7Ba0.3MnO3}$
}

\begin{abstract}
In this work, $\mathrm{Nd} 0.7 \mathrm{Ba} 0.3 \mathrm{MnO} 3$ was synthesized via cryo-milling method to investigate the effect of calcination temperature on the structure, microstructure, magnetic and electrical properties. XRD analysis revealed all samples can be indexed to orthorhombic structure systems with Imma space group accompany with some minor phases of Mn2O4 and $\mathrm{BaMnO3}$. FESEM analysis confirmed that a slight increase in the grain size from $117.4 \mathrm{~nm}$ $\left(600^{\circ} \mathrm{C}\right), 119.5 \mathrm{~nm}\left(700^{\circ} \mathrm{C}\right), 121.0 \mathrm{~nm}\left(800^{\circ} \mathrm{C}\right), 123.1 \mathrm{~nm}\left(900^{\circ} \mathrm{C}\right)$ to $138.4 \mathrm{~nm}\left(1000^{\circ} \mathrm{C}\right)$ was observed when different calcination temperature was applied. Four Point Probe measurements showed that all samples are in paramagnetic insulating region and TMIT is lower than 20K. Resistivity increase when grain size reduces due to increase of effective grain boundary that weakens the electron hopping process via double exchange mechanism. Beside, a drastic increase of resistivity also observed due to present of minor secondary phase (BaMnO3) in sample C9.
\end{abstract}

Keyword: Calcination temperature; Grain size; Manganites 